\title{
Head and neck cutaneous melanoma: 5- year survival analysis in a Serbian university center
}

\author{
Aleksandar Višnjić ${ }^{1,2}$, Predrag Kovačević ${ }^{3,4}$, Asen Veličkov ${ }^{5}$, Mariola Stojanović ${ }^{2}$ and Stefan Mladenović ${ }^{4 *}$ (D)
}

\begin{abstract}
Background: Head and neck melanoma (HNM) is specific from the anatomical and etiopathogenetic aspects. In addition to morphopathological parameters, rich vascularization and lymphatic drainage of the head and neck affect the occurrence of lymphogenic and hematogenous metastases, as well as the metastases on both sides of the neck.

Methods: A retrospective cross-sectional study included cutaneous melanoma patients who underwent surgery at a clinical center over a 10-year period. The clinical follow-up was at least 60 months. The Kaplan-Meier method was used for the survival analysis. The predictor effect of certain independent variables on a given dichotomous dependent variable (survival) was measured by the Cox regression analysis.

Results: The analysis of demographic and clinical characteristics of 116 patients with HNM revealed that there was no statistically significant difference in age and gender in the total sample. Thirty-three (28.45\%) patients were already in stage III or IV of the disease at the first examination, which affected the overall survival rate. The overall 5-year survival was $30.2 \%$. No statistically significant difference in 5-year survival was found in relation to age and location. The period without melanoma progression decreased progressively in the advanced stage. Forty-nine patients (42\%) underwent surgery for lymphogenic metastases in the parotid region and/or neck during the follow-up.

Conclusions: Patients with HNM included in this study frequently presented an advanced stage of the disease at the first examination, which is reflected in a low rate of 5 -year survival. Early diagnosis and adequate primary treatment can ensure longer survival.
\end{abstract}

Keywords: Melanoma, Head and neck, Survival, Predictors

\section{Background}

Melanoma is one of the most malignant tumors in human population and the most malignant skin tumor. The incidence of melanoma varies around the world, and it has been steadily rising in recent decades. An increase of up to $200 \%$ over the last 20 years has been reported [1]. The increase in incidence is higher in males than in females [2].

\footnotetext{
* Correspondence: fahste1990@yahoo.com

${ }^{4}$ Clinic for Plastic and Reconstructive Surgery, Clinical Centre of Niš, Niš 18000, Serbia

Full list of author information is available at the end of the article
}

Head and neck melanoma is specific in two aspects: anatomical and etiopathogenetic. In addition to local infiltration, which is assessed on the basis of a number of parameters (tumor thickness, number of mitoses, lymphovascular invasion, satellitosis), rich vascularization and lymphatic drainage of the head and neck affect the occurrence of lymphogenic and hematogenous metastases, as well as metastases on both sides of the neck in melanoma near the sagittal plane. The main prognostic factor is the thickness of the tumor. With the increase in the thickness of the tumor, the risk of developing lymphogenic metastases increases [3]. Metastases in the 
lymph nodes of the neck and parotid region, as well as lymph nodes in the occipital region for melanoma in the occipital region, are typical. The distribution of melanoma localization is as follows: face (52\%), scalp (19\%), neck (17\%), ear (9\%), and mucosal lesions (3\%) [4]. The clinical course also depends on the localization of the primary tumor; therefore, the localization on the earlobe and scalp is mentioned as a risk factor for an aggressive clinical course. For head and neck melanoma, males are associated with a worse prognosis, while melanoma on the face mainly does not cause metastases $[5,6]$. The etiology of head and neck melanoma is related to the exposure to UV radiation as an important factor. The head and neck area accounts for 9\% of body surface area, while the prevalence of melanoma of these regions is higher $[5,6]$.

The median age at diagnosis was about 60 years, but a quarter of patients were younger than 45 [7]. Early diagnosis and adherence to established treatment guidelines significantly affect survival in these patients [8].

The American Joint Committee on Cancer (AJCC) assigns the following important factors: tumor thickness and ulceration for $\mathrm{T}$ category, the number of lymph nodes with micro or macro metastases, satellite infiltrations or in transit metastases for $\mathrm{N}$ category, and the presence of distant metastases and/or elevated plasma LDH levels for M category $[9,10]$.

Surgical treatment is the gold standard for treating cutaneous melanoma. Treatment of melanoma begins with an excisional biopsy. After the diagnosis is confirmed, the stage of the disease is determined. Then, a wide excision of the tumor is applied. Surgical margins of healthy tissue are defined as follows: for in situ melanoma $5 \mathrm{~mm}$, for melanoma up to $1 \mathrm{~mm}$ it is $1 \mathrm{~cm}$, and for the rest, the margin is $2 \mathrm{~cm}$ in the healthy tissue [11, 12]. The use of sentinel node biopsy is controversial. According to reports, it is performed in only $5-7 \%$ of all head and neck melanomas, and some studies show no difference in survival with or without sentinel biopsy [13-16]. Therapeutic dissections are performed when lymph node enlargement is clinically and radiologically confirmed. Dissection can be classified as radical neck dissection, modified radical neck dissection, or extended neck dissection. When clinically indicated, parotidectomy is performed in the form of a superficial parotidectomy, for melanoma in the parotid masseteric region and in front of a vertical line passing through the external auditory canal. In melanomas located in front of a vertical line passing through the external auditory canal, a dissection of the I-IV group of neck nodes is performed. For melanoma behind the vertical line through the external auditory canal, a posterolateral dissection is performed, which includes group $\mathrm{V}$ of the neck nodes and postauricular and suboccipital nodes [17]. In clinically positive metastases in the parotid region, some authors suggest elective neck dissection because they found the existence of occult metastases in $38 \%$ of patients [18].

Five-year survival for scalp and neck cutaneous melanoma has been on the rise recently $(93.9 \%$ cases have been reported). However, in positive lymph nodes, survival is up to $83.1 \%$, which is lower than in other anatomical regions. In relation to tumor thickness, for T1 disease-specific, 5 -year survival (5-year DS) is $96.7 \%$ and for T4 it is $62.3 \%[19,20]$.

The aim of this paper is to analyze the incidence of head and neck melanoma in the total population of cutaneous melanoma and determine the prognostic significance of gender, age, localization, and disease stage at a 5 -year survival rate. The period without disease progression and the type of surgery during the follow-up are also shown.

\section{Methods}

The retrospective cross-sectional study includes patients with cutaneous melanoma over a 10 -year period who underwent surgery at a university clinical center in Niš, Serbia. Patients with melanoma of the head and neck were selected from the medical reports. Demographic characteristics (gender, age), localization of melanoma, and TNM classification according to the American Joint Committee on Cancer (TNM classifications for cutaneous melanoma, eighth edition) [9] were analyzed. The stage of the disease was defined during conciliar examination, and all patients were clinically monitored at the oncology advisory board for at least 60 months. It was determined whether lymphogenic or hematogenous metastases and melanoma-specific mortality occurred.

The study procedures were carried out in accordance with the Declaration of Helsinki, and approvals of the Ethical Committee of the Faculty of Medicine of the University of Niš.

\section{Statistical analysis}

The following statistical parameters are presented by descriptive statistical analysis: arithmetic mean, standard deviation, coefficient of variation, absolute frequency $(n)$, and structure index (\%). The comparison of the frequency of occurrence of individual modalities of attribute features between groups was performed by Pearson $x^{2}$ test/Fisher exact test. The comparison of the mean values of the numerical features between the two independent groups of respondents was performed by Student's $t$ test or MannWhitney $U$ test. To measure the correlation of certain traits, a Pearson correlation analysis was performed. The Kaplan-Meier method was used for survival analysis. The predictor effect of certain independent variables on a given dichotomous dependent variable (survival) was measured by Cox regression analysis.

Statistical analysis was performed using SPSS program version 18.0 (SPSS Inc., Chicago, IL, USA). The threshold 
for statistical significance was the level of statistical error less than $5 \%(p<0.05)$. The results of the statistical analysis are presented in tables and graphs.

\section{Results}

In the period from 2005 to 2015, a total of 774 patients with cutaneous melanoma were registered at the oncology advisory board of the University Clinical Center of Niš (Serbia), and 116 of them were diagnosed with head and neck cutaneous melanoma (14.99\%). Demographic and clinical characteristics of patients with head and neck melanoma are given in Table 1.

The Student $t$ test shows that there was no statistically significant difference in age and gender in the total sample $(p=0.9)$. Melanoma was most often diagnosed in persons aged 50 to 80 years. The most common localization was on the face. Unfortunately, a significantly large number had an advanced stage of the disease with already present lymphogenic and/or hematogenous metastases at the first examination (stages III and IV were diagnosed in 33 patients) (Table 1).

The distribution of the location in relation to gender differs significantly for tumors on the face and scalp. Namely, $40 \%$ of all melanomas in males is on the scalp, while $55 \%$ of melanomas in females is on the face (Pearson $X^{2}=13.102, p=0.004$ ).

The overall 5 -year survival is $30.2 \%$ (Table 2). It is statistically significantly higher in females (Mann-Whitney

Table 1 Demographic and clinical characteristics of patients

\begin{tabular}{|c|c|c|c|}
\hline & Number & Mean age (years) & Std. deviation \\
\hline \multicolumn{4}{|l|}{ Gender } \\
\hline Male & 67 & 61.78 & 13.62 \\
\hline \multirow[t]{3}{*}{ Female } & 49 & 61.45 & 14.35 \\
\hline & Gender & & \\
\hline & Male & Female & Total \\
\hline \multicolumn{4}{|l|}{ Age } \\
\hline$<30$ & 1 & 2 & 3 \\
\hline $31-40$ & 4 & 2 & 6 \\
\hline $41-50$ & 10 & 7 & 17 \\
\hline $51-60$ & 16 & 12 & 28 \\
\hline $61-70$ & 14 & 11 & 25 \\
\hline $71-80$ & 18 & 10 & 28 \\
\hline $81+$ & 4 & 5 & 9 \\
\hline \multirow[t]{2}{*}{ Total } & 67 & 49 & 116 \\
\hline & Male $(n, \%)$ & Female $(n, \%)$ & Total \\
\hline \multicolumn{4}{|l|}{ Location } \\
\hline Face & $23(34.3 \%)$ & $27(55.1 \%)$ & 50 (43.1\%) \\
\hline Scalp & 27 (40.3\%) & $5(10.2 \%)$ & $32(27.6 \%)$ \\
\hline Ear & $6(9,0 \%)$ & $5(10,2 \%)$ & $11(9,5 \%)$ \\
\hline Neck & $11(16.4 \%)$ & $12(24.5 \%)$ & $23(19.8 \%)$ \\
\hline \multirow[t]{2}{*}{ Total } & $67(100.0 \%)$ & 49 (100.0\%) & $116(100.0 \%)$ \\
\hline & Male & Female & Total \\
\hline \multicolumn{4}{|l|}{ Stage } \\
\hline $\mid \mathrm{A}$ & $6(8.96 \%)$ & $11(22.45 \%)$ & $17(14.66 \%)$ \\
\hline $\mathrm{IB}$ & 17 (25.37\%) & $11(22.45 \%)$ & $28(24.14 \%)$ \\
\hline$\| \mathrm{A}$ & $13(19.40 \%)$ & $9(18.37 \%)$ & $22(18.97 \%)$ \\
\hline$\| \mathrm{B}$ & $4(5.97 \%)$ & $3(6.12 \%)$ & 7 (6.03\%) \\
\hline$\| C$ & 4 (5.97\%) & $5(10.20 \%)$ & $9(7.76 \%)$ \\
\hline III & $14(20.90 \%)$ & $8(16.33 \%)$ & $22(18.97 \%)$ \\
\hline IV & 9 (13.43\%) & $2(4.08 \%)$ & 11 (9.48\%) \\
\hline Total & 67 (100.00\%) & 49 (100.00\%) & $116(100.00 \%)$ \\
\hline
\end{tabular}


Table 2 Five-year survival by gender in total

\begin{tabular}{|c|c|c|c|c|}
\hline \multirow{2}{*}{$\begin{array}{l}\text { 60-month } \\
\text { survival }\end{array}$} & & \multicolumn{2}{|l|}{ Gender } & \multirow[t]{2}{*}{ Total } \\
\hline & & $M$ & $F$ & \\
\hline Died & $n(\%)$ & $51(76.1 \%)$ & $30(61.2 \%)$ & 81 (69.8\%) \\
\hline Survived & & 16 (23.9\%) & 19 (38.8\%) & $35(30.2 \%)$ \\
\hline Total & & 67 (100.0\%) & 49 (100.0\%) & 116 (100.0\%) \\
\hline
\end{tabular}

$U$ test, $p=0.020$ ). In our sample, female patients lived on average 9 months longer than male patients.

There is no statistically significant difference in 5-year survival in relation to age ( $T$ test, $p=0.204)$ and localization ( $\chi^{2}$ test, $p=0.323$ ), but survival is significantly shorter if lymphogenic or hematogenous metastases (stages III and IV) were reported at the first surgeon's examination ( $\chi^{2}$ test, $p<0.001$ ) (Table 3 ).

The disease-free interval was calculated for a follow-up period of 60 months, regardless of the fact that in some patients the follow-up period was significantly longer (up to 150 months). The period without melanoma progression decreases progressively in the advanced stage, and the occurrence of parenchymal metastases is more frequent in later stages (Table 4). Based on the decision of the oncology advisory board, specific oncological therapy was determined for parenchymal metastases (29 patients).

Forty-nine patients (42\%) underwent surgery for lymphogenic metastases in the parotid region and/or neck and superficial parotidectomy and radical neck dissection were performed (Table 5). In patients with stage III, extensive excision and radical neck dissection were simultaneously performed during the first surgery. During the follow-up of patients in stage III, six patients underwent neck surgery, including four reoperations on the same side of the neck, and two patients underwent dissection on the contralateral side of the neck.

Kaplan-Meier and Cox regression analysis were used to monitor the prognosis of patient survival in relation to the examined factors. Kaplan-Meier analysis (Fig. 1a) indicates a better prognosis in females $(p=0.031)$, while the localization of melanoma (Fig. 1b) does not affect survival $(p=0.253)$.

Table 3 Disease stage and 5-year survival

\begin{tabular}{llll}
\hline Stage & Died $\boldsymbol{n}(\%)$ & Survived $\boldsymbol{n}(\%)$ & Total $\boldsymbol{n}(\%)$ \\
\hline IA & $1(1.2)$ & $16(45.7)$ & $17(14.7)$ \\
IB & $16(19.8)$ & $12(34.3)$ & $28(24.1)$ \\
IIA & $16(19.8)$ & $6(17.1)$ & $22(19.0)$ \\
IIB & $6(7.4)$ & $1(2.9)$ & $7(6.0)$ \\
IIC & $9(11.1)$ & $0(0)$ & $9(7.8)$ \\
III & $22(27.2)$ & $0(0)$ & $22(19.0)$ \\
IV & $11(13.6)$ & $0(0)$ & $11(9.5)$ \\
Total & $81(100.0)$ & $35(100.0)$ & $116(100.0)$ \\
\hline
\end{tabular}

Cox regression analysis of survival predictors (backward stepwise method) indicates that the presence of metastases at the first examination, higher Breslow thickness, and higher number of nearby lymph nodes that have cancer $(\mathrm{N})$ are predictors of poor survival. Size of the primary tumor $(\mathrm{T})$, although seemingly with a pronounced prognostic value $(\mathrm{HR}=1.524)$, is at the very limit of statistical significance $(p=0.047 ; 95 \% \mathrm{CI}=$ 1.005-2.311), so it still cannot be interpreted as one of the predictors. Gender was also not a significant predictor of survival (Table 6). Localization of tumor, presence of distant metastasis (M), Clark level, and disease-free period (DFP) were as variables removed from the model at previous steps of the backward stepwise Cox regression analysis as non significant.

\section{Discussion}

Our study included patients with head and neck melanoma (HNM) followed in the 5-year period from diagnosis. A total of 116 patients with HNM makes up 14.99\% of all melanoma patients in the same time period, which represents a lower prevalence of HNM than in other studies [7]. HNM is more common in males (57.76\%) and people older than 50 years $(77.59 \%)$, but neither of the abovementioned predictors affects survival. El Sharouni et al. in a study of 54,645 patients point out to male gender as an important predictor of disease outcome [21]. The total 5-year survival in our sample is $30.2 \%$, which is far less than the results in other studies $[19,20]$. Reduced 5-year survival in our sample is associated with a large number of patients who consulted a doctor in an already advanced stage of the disease with present metastases (as many as $28.45 \%$ of patients in stages III and IV). Higher Breslow thickness, higher degree of tumor spread to regional lymph nodes $(\mathrm{N})$, and the presence of metastases at the first examination were highlighted as predictors for the poor outcome. They significantly affect the progressive reduction of the disease-free period, which corresponds to the results of other authors [3, 7, 22].

Our study showed that the primary localization of melanoma did not affect 5-year survival. The results of other studies indicate that melanoma of the scalp has a more aggressive clinical course with more frequent local recurrences, shorter disease-free period, and almost twice the chance of disease progression [22-25]. The conclusions of other authors on the influence of scalp melanoma on 5-year survival are divided. According to some authors, these localisation of primary melanoma do not make a significant difference in 5-year survival compared to melanoma of other head and neck regions [25-28], while Ozao-Choy et al. indicate that melanoma of the scalp significantly adversely affects 5-year survival 
Table 4 Disease stage and disease-free period

\begin{tabular}{|c|c|c|c|c|c|}
\hline Stage & $\begin{array}{l}\text { Number of } \\
\text { patients }\end{array}$ & $\begin{array}{l}\text { Mean DF } \\
\text { (months) }\end{array}$ & $\begin{array}{l}\text { Location of } \\
\text { metastasis }\end{array}$ & $\begin{array}{l}\text { Number of } \\
\text { patients }\end{array}$ & $\begin{array}{l}\text { Period until the occurrence } \\
\text { of metastasis (months) }\end{array}$ \\
\hline $\mathrm{IA}$ & 17 & 57.58 & $\mathrm{~N}$ & 1 & 19 \\
\hline \multirow[t]{2}{*}{ IB } & 28 & 33.89 & $M$ & 2 & $2-60$ \\
\hline & & & $N$ & 19 & \\
\hline \multirow[t]{2}{*}{$\| \mathrm{A}$} & 22 & 21.81 & $M$ & 5 & $6-50$ \\
\hline & & & $N$ & 13 & \\
\hline \multirow[t]{2}{*}{$\| \mathrm{B}$} & 7 & 19 & $M$ & 2 & $6-40$ \\
\hline & & & $\mathrm{N}$ & 5 & \\
\hline \multirow[t]{2}{*}{$\| C$} & 9 & 11 & $M$ & 4 & $4-20$ \\
\hline & & & $\mathrm{N}$ & 5 & \\
\hline \multirow[t]{2}{*}{ III } & 22 & 9 & $M$ & 16 & $1-32$ \\
\hline & & & $\mathrm{N}$ & 6 & \\
\hline IV & 11 & 0 & $\mathrm{~N} / \mathrm{A}$ & & N/A \\
\hline \multirow[t]{2}{*}{ Total } & 116 & N/A & $M$ & 29 & N/A \\
\hline & & & $N$ & 49 & \\
\hline
\end{tabular}

$D F$ disease free, $M$ parenchymal metastases, $N$ lymphogenic metastases

compared to melanoma of other localizations of the head and neck [29, 30].

Den Hondt et al. in their paper point out the importance of elective neck dissection in patients with metastases in the parotid region. In our sample, $18 \%$ of patients with metastases had metastases in the parotid region of which as many as $89 \%$ of patients had failure in cervical nodes. Elective neck dissection not only reduces failure rates in cervical nodes but also provides more accurate information about the stage of the disease and prognosis [31].

Radical neck dissection (RND) was performed in 70 patients with clinically and ultrasonographically proven positive lymph nodes. In 22 patients who were in stage III at the first examination, RND was performed in the same act as radical excision of cutaneous melanoma. In other 48 patients, RND was performed during a followup, four of whom underwent redissection. The literature shows a great range in recurrence rates after neck dissection (from 0 to 43\%) [16, 32-37]. In a study with a similar number of patients, Andersen et al. [38] stated that the recurrence rate after RND was $11 \%$, which is similar to the percentage in our sample $(6.06 \%)$. One interesting fact from our sample is that recurrences after RND occurred only in patients who were in stage III at the first examination, while in patients who underwent RND during the follow-up, there were no recurrences.

Song et al. indicate the importance of using systemic therapy in patients who were in the third stage of the

Table 5 Disease stage and location of lymphogenic metastases

\begin{tabular}{llll}
\hline Stage & Number of patients & $\begin{array}{l}\text { Location of lymphogenic } \\
\text { metastases }\end{array}$ & $\begin{array}{l}\text { Number of surgeries } \\
\text { after initial treatment }\end{array}$ \\
\hline IA & 17 & Neck & 1 \\
IB & 28 & Parotid & 1 \\
& & Neck & 13 \\
IIA & 22 & Parotid and neck & 5 \\
IIB & 7 & Parotid and neck & 3 \\
IIC & 9 & Neck & 10 \\
III & 22 & Neck & 5 \\
IV & 11 & Neck & 5 \\
Total & 116 & Neck & 6 \\
& & N/A & N/A \\
\end{tabular}




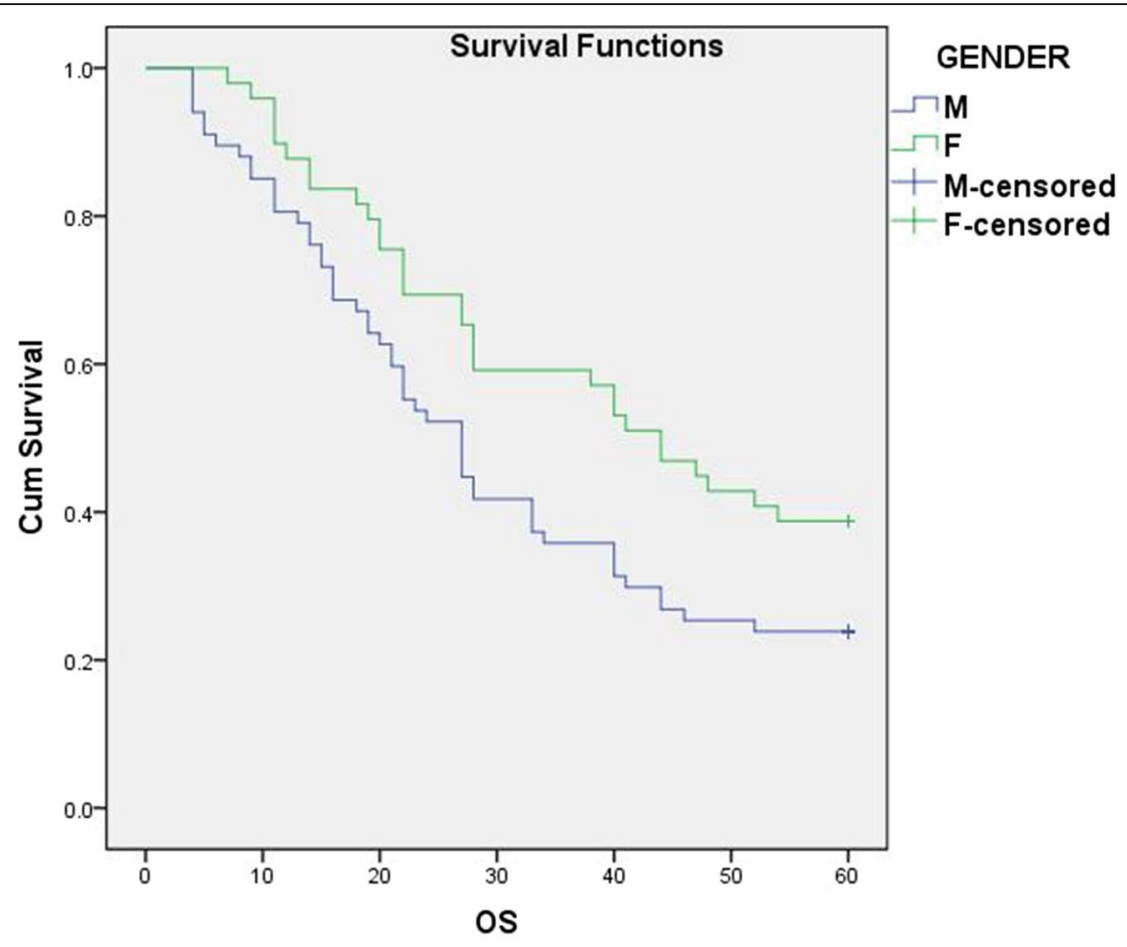

a. Kaplan-Meier data analysis in relation to gender of patients

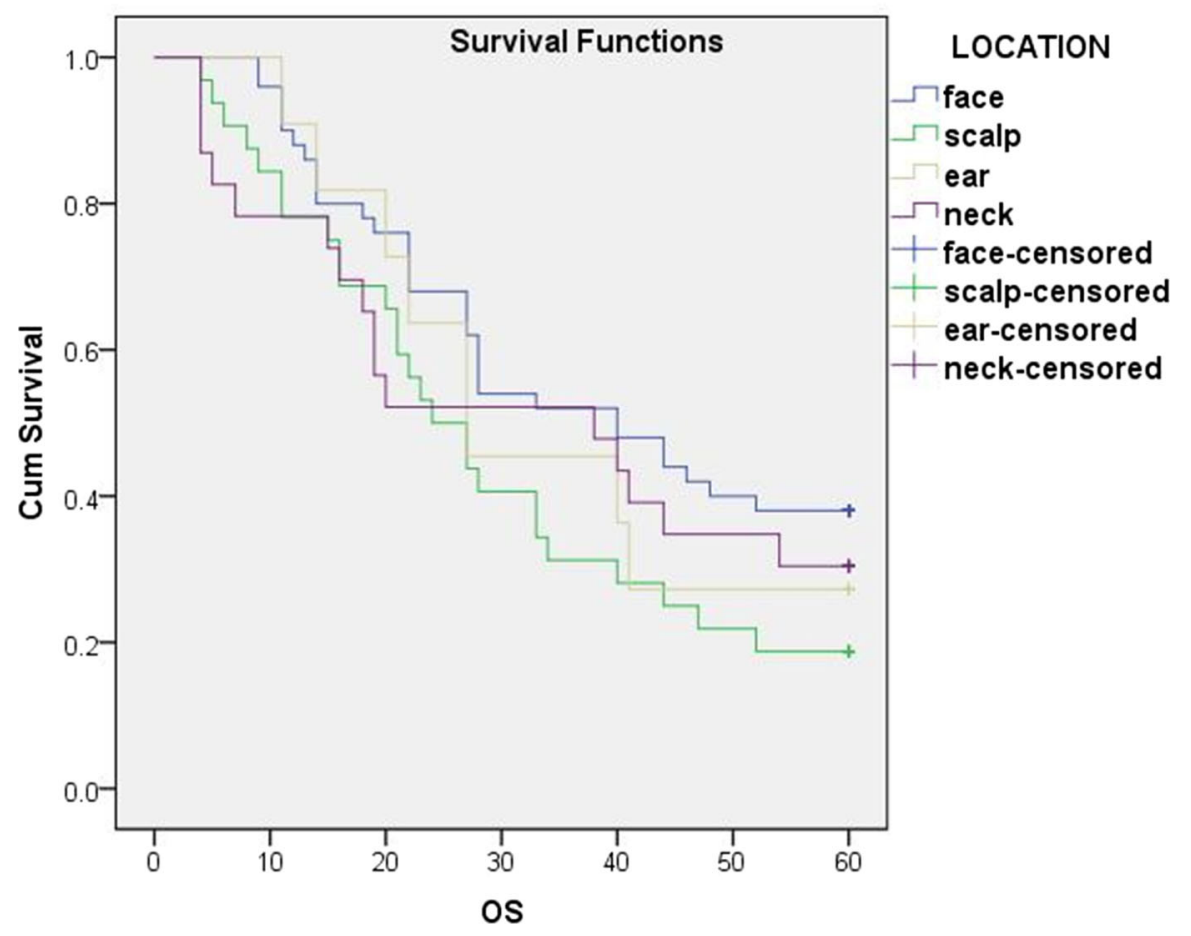

b. Kaplan-Meier data analysis in relation to location of melanoma

Fig. 1 a Kaplan-Meier data analysis in relation to gender of patients. $\mathbf{b}$ Kaplan-Meier data analysis in relation to location of melanoma 
Table 6 Cox regression survival predictor analysis

\begin{tabular}{lllllllll}
\hline Predictors & B & SE & Wald & df & $p$ & HR & \multicolumn{2}{c}{\begin{tabular}{l}
$\mathbf{9 5 . 0 \%}$ Cl \\
\cline { 6 - 9 }
\end{tabular}} \\
& & & & & & Lower & Upper \\
\hline M first ex & -1.568 & 0.339 & 21.362 & 1 & 0.000 & 0.208 & 0.107 & 0.405 \\
Breslow & -0.832 & 0.287 & 11.232 & 1 & 0.005 & 0.375 & 0.245 & 0.672 \\
$\mathrm{~T}$ & 0.421 & 0.212 & 3.931 & 1 & 0.047 & 1.524 & 1.005 & 2.311 \\
$\mathrm{~N}$ & -0.372 & 0.142 & 6.891 & 1 & 0.009 & 0.689 & 0.522 & 0.910 \\
Gender & 0.424 & 0.252 & 2.835 & 1 & 0.092 & 1.528 & 0.933 & 2.502 \\
\hline
\end{tabular}

$B$ coefficient for the constant in the null model, $H R$ hazard ratio, $M$ first ex the presence of metastases at the first examination, Breslow Breslow depth, $T$ size and extent of the main tumor, $N$ degree of spread to regional lymph nodes (in TNM classification)

disease at the time of the first examination due to the fact that recurrences in the lymph nodes occur more often in these patients and they have a poorer prognosis. The use of systemic therapy in these patients significantly improves 5 -year survival [39].

However, since the incidence of head and neck cutaneous melanoma continues to increase all over the world, and that it dramatically affects quality of life both in patients and caregivers, the primary prevention and early diagnosis should become a priority [40, 41]. Excessive sun exposure and overuse of solarium have been established as the major cause of cutaneous melanoma, so the effect of health education on this behavior could be valuable, along with the secondary prevention measures of particularly at risk populations [42-44].

\section{Conclusions}

Patients with head and neck melanoma included in this study very often presented melanoma in an advanced stage of the disease at the first examination, which caused the low rate of 5-year survival. Treatment of head and neck melanoma is a great challenge due to frequent metastases to lymph nodes and the development of distant metastases. Therefore, in addition to adequate oncosurgical treatment, it is necessary to pay attention to postoperative monitoring and further treatment in accordance with treatment protocols.

\section{Acknowledgements}

This work was supported by the Ministry of Science and Technological Development of the Republic of Serbia (Project 43012 and Project 41018)

\footnotetext{
Authors' contributions

Conceptualization, AV and PK; methodology, AV and MS; software, MS; validation, $A V, P K$, and $A V$; formal analysis, $A V, A V$, and $M S$; investigation, $A V$ and $\mathrm{SM}$; resources, $\mathrm{AV}$ and $\mathrm{SM}$; writing - original draft preparation, $\mathrm{AV}, \mathrm{PK}$, and $A V$; writing - review and editing, $A V, P K, A V$, and $S M$; visualization, SM; supervision, AV, PK, AV, MS, and SM; project administration, PK, AV, and SM. All authors have read and agreed to the published version of the manuscript.
}

\section{Funding}

This research received no external funding.

\section{Availability of data and materials}

The datasets used and analyzed during the current study are available from the corresponding author on reasonable request.

\section{Ethics approval and consent to participate}

The study procedures were carried out in accordance with the Declaration of Helsinki and approval of the Ethical Committee of the Faculty of Medicine of the University of Niš.

\section{Consent for publication}

Written informed consent from the patients was obtained.

\section{Competing interests}

The authors declare no conflict of interest.

\section{Author details}

${ }^{1}$ Department of Social Medicine, Faculty of Medicine, University of Niš, Niš 18000, Serbia. ${ }^{2}$ Institute of Public Health of Niš, Niš 18000, Serbia.

${ }^{3}$ Department of Surgery, Faculty of Medicine, University of Niš, Niš 18000, Serbia. ${ }^{4}$ Clinic for Plastic and Reconstructive Surgery, Clinical Centre of Niš, Niš 18000, Serbia. ${ }^{5}$ Trauma and Reconstructive Surgery, Orthopedics, Kreisklinik Roth, Roth 91154, Germany.

Received: 28 August 2020 Accepted: 23 November 2020

Published online: 29 November 2020

\section{References}

1. Weinstock MA. Epidemiology, etiology, and control of melanoma. Med Health R I. 2001;84(7):234-6.

2. National Cancer Institute. Surveillance, epidemiology, and end results. Available online: https://seer.cancer.gov/statfacts/html/melan.html (Accessed on 8 Oct 2020).

3. Uslu U, Schuler G, Breuninger $H$. Factors influencing disease progression in patients with head and neck melanoma. Anticancer Res. 2017:37(7):3811-6.

4. Shaw JHF, Fay M. Management of head and neck melanoma, treatment of metastatic melanoma. Morton R, editor. InTech; 2011. Available from: http:// www.intechopen.com/books/treatment-of-metastatic-melanoma/ management-of-head-andneckmelanoma. ISBN: 978-953-307-574-7.

5. Balch CM, Gershenwald JE, Soong SJ, et al. Final version of 2009 AJCC melanoma staging and classification. J Clin Oncol. 2009;27(36):6199-206.

6. Retsas S, Henry K, Mohammed MQ, MacRae K. Prognostic factors of cutaneous melanoma and a new staging system proposed by the American Joint Committee on Cancer (AJCC): validation in a cohort of 1284 patients. Eur J Cancer. 2002;38(4):511-6.

7. Al-Qurayshi Z, Hassan M, Srivastav S, et al. Risk and survival of patients with head and neck cutaneous melanoma: national perspective. Oncology. 2017; 93(1):18-28.

8. OW TJ, Grethlein SJ, Schmalbach CE. Education Committee of the American Head and Neck Society (AHNS). Do you know your guidelines? Diagnosis and management of cutaneous head and neck melanoma. Head Neck. 2018;40(5):875-85.

9. Gershenwald JE, Scolyer RA. Melanoma staging: American Joint Committee on Cancer (AJCC) 8th edition and beyond. Ann Surg Oncol. 2018;25(8): 2105-10.

10. AJCC Staging Manuals. Available online: http://cancerstaging.org/referencestools/deskreferences/Documents/AJCC\%207th\%20Ed\%20Cancer\%2 OStaging\%20Manual.pdf (Accessed on 8 Oct 2020).

11. Yao K, Balch G, Winchester DJ. Multidisciplinary treatment of primary melanoma. Surg Clin North Am. 2009;89(1):267-xi.

12. Balch $C M$, Urist $M M$, Karakousis $C P$, et al. Efficacy of 2-cm surgical margins for intermediate-thickness melanomas (1 to $4 \mathrm{~mm}$ ). Results of a multiinstitutional randomized surgical trial. Ann Surg. 1993;218(3):262-9.

13. Möhrle M, Schippert W, Rassner G, Garbe C, Breuninger H. Is sentinel lymph node biopsy of therapeutic relevance for melanoma? Dermatology. 2004; 209:5-13.

14. Medalie N, Ackermann AB. Sentinel node biopsy has no benefit for patients whose primary cutaneous melanoma has metastasized to a lymph node and therefore should be abandoned now. Br J Dermatol. 2004;151:298-307.

15. Balch CM, Cascinelli N. Sentinel- node biopsy in melanoma. N Engl J Med. 2006;355:1370-1. 
16. Tanis PJ, Nieweg OE, van den Brekel MW, Balm AJ. Dilemma of clinically node-negative head and neck melanoma: outcome of "watch and wait" policy, elective lymph node dissection, and sentinel node biopsy - a systematic review. Head Neck. 2008:30:380-9.

17. National Comprehensive Cancer Network. Guidelines for patients: melanoma. Available online: https://www.nccn.org/patients/guidelines/ content/PDF/melanoma-patient.pdf (Accessed on 8 Oct 2020).

18. O'Brien CJ, McNeil EB, MCMahon JD, Pathak I, Lauer CS. Incidence of cervical node involvement in metastatic cutaneous malignancy involving the parotid gland. Head Neck. 2001;23:744-8.

19. Ch'ng S, Pinna A, loannou K, Juszczyk K, Shannon K, Clifford A, Uren R, Clark $J R$. Assessment of second tier lymph nodes in melanoma and implications for extent of elective neck dissection in metastatic cutaneous malignancy of the parotid. Head Neck. 2013;35(2):205-8.

20. Lachiewicz AM, Berwick M, Wiggins $C L$, Thomas NE. Survival differences between patients with scalp or neck melanoma and those with melanoma of other sites in the Surveillance, Epidemiology, and End Results (SEER) program. Arch Dermatol. 2008;144(4):515-21.

21. El Sharouni MA, Witkamp AJ, Sigurdsson V, van Diest PJ, Louwman MWJ, Kukutsch NA. Sex matters: men with melanoma have a worse prognosis than women. J Eur Acad Dermatol Venereol. 2019;33(11):2062-7.

22. Terakedis BE, Anker CJ, Leachman SA, et al. Patterns of failure and predictors of outcome in cutaneous malignant melanoma of the scalp. J Am Acad Dermatol. 2014;70(3):435-42.

23. Leong SP, Accortt NA, Essner R, et al. Impact of sentinel node status and other risk factors on the clinical outcome of head and neck melanoma patients. Arch Otolaryngol Head Neck Surg. 2006;132(4):370-3.

24. O'Brien CJ, Coates AS, Petersen-Schaefer K, et al. Experience with 998 cutaneous melanomas of the head and neck over 30 years. Am J Surg. 1991;162(4):310-4.

25. Shumate CR, Carlson GW, Giacco GG, et al. The prognostic implications of location for scalp melanoma. Am J Surg. 1991;162(4):315-9.

26. de Giorgi V, Rossari S, Gori A, et al. The prognostic impact of the anatomical sites in the 'head and neck melanoma': scalp versus face and neck. Melanoma Res. 2012;22(5):402-5.

27. Parrett BM, Kashani-Sabet M, Singer Ml, et al. Long-term prognosis and significance of the sentinel lymph node in head and neck melanoma. Otolaryngol Head Neck Surg. 2012;147(4):699-706.

28. Cappello ZJ, Augenstein AC, Potts KL, et al. Sentinel lymph node status is the most important prognostic factor in patients with melanoma of the scalp. Laryngoscope. 2013;123(6):1411-5.

29. Ozao-Choy J, Nelson DW, Hiles J, Stern S, Yoon JL, Sim MS, Faries MB. The prognostic importance of scalp location in primary head and neck melanoma. J Surg Oncol. 2017;116(3):337-43.

30. Xie C, Pan Y, McLean C, Mar V, Wolfe R, Kelly J. Impact of scalp location on survival in head and neck melanoma: a retrospective cohort study. J Am Acad Dermatol. 2017;76(3):494-498.e2.

31. Den Hondt M, Starr MW, Millett MC, Smyth J, Scolyer RA, Shannon KF, Thompson JF, Ch'ng S. Surgical management of the neck in patients with metastatic melanoma in parotid lymph nodes. J Surg Oncol. 2019;120(8): 1462-9.

32. Mack LA, McKinnon JG. Controversies in the management of metastatic melanoma to regional lymphatic basins. J Surg Oncol 2004;86:189-99.

33. White $\mathrm{N}$, Yap LH, Srivastava S. Lymphadenectomy for melanoma in the clinically N1 neck: radical, modified radical, or selective? J Craniofac Surg. 2009;20:385-8.

34. Turkula LD, Woods JE. Limited or selective nodal dissection for malignant melanoma of the head and neck. Am J Surg. 1984;148:446-8.

35. Van de Vrie W, Eggermont AM, Van Putten WL, et al. Therapeutic lymphadenectomy in melanomas of the head and neck. Head Neck. 1993; 15:377-81.

36. Jonk A, Strobbe $L$, Kroon BB, et al. Cervical lymphnode metastasis from cutaneous melanoma of the head and neck: a search for prognostic factors. Eur J Surg Oncol. 1998;24:298-302.

37. Shen $\mathrm{P}$, Wanek LA, Morton DL. Is adjuvant radiotherapy necessary after positive lymph node dissection in head and neck melanomas? Ann Surg Oncol. 2000;7:554-9.

38. Andersen PS, Chakera AH, Thamsborg AK, et al. Recurrence and survival after neck dissections in cutaneous head and neck melanoma. Dan Med J. 2014;61(12):A4953.
39. Song Y, Tieniber AD, Gimotty PA, Mitchell TC, Amaravadi RK, Schuchter LM, Fraker DL, Karakousis GC. Survival outcomes of patients with clinical stage III melanoma in the era of novel systemic therapies. Ann Surg Oncol. 2019; 26(13):4621-30.

40. Berwick M, Buller DB, Cust A, Gallagher R, Lee TK, Meyskens F, Pandey S, Thomas NE, Veierød MB, Ward S. Melanoma epidemiology and prevention. Cancer Treat Res. 2016;167:17-49.

41. Resteghini C, Trama A, Borgonovi E, Hosni H, Corrao G, Orlandi E, Calareso G, De Cecco L, Piazza C, Mainardi L, Licitra L. Big data in head and neck cancer. Curr Treat Options Oncol. 2018;19(12):62.

42. Cohen N, Fedewa S, Chen AY. Epidemiology and demographics of the head and neck cancer population. Oral Maxillofac Surg Clin North Am. 2018;30(4): 381-95.

43. Sterba KR, Zapka J, Cranos C, Laursen A, Day TA. Quality of life in head and neck cancer patient-caregiver dyads: a systematic review. Cancer Nurs. 2016; 39(3):238-50.

44. Gilmore S. Melanoma screening: informing public health policy with quantitative modelling. PLoSONE. 2017;12(9):e0182349.

\section{Publisher's Note}

Springer Nature remains neutral with regard to jurisdictional claims in published maps and institutional affiliations.
Ready to submit your research? Choose BMC and benefit from:

- fast, convenient online submission

- thorough peer review by experienced researchers in your field

- rapid publication on acceptance

- support for research data, including large and complex data types

- gold Open Access which fosters wider collaboration and increased citations

- maximum visibility for your research: over $100 \mathrm{M}$ website views per year

At BMC, research is always in progress.

Learn more biomedcentral.com/submissions 